\title{
Fostering scientific curiosity through strengthening teachers' understanding of energy and inquiry
}

\author{
M. E. Zayed ${ }^{1}$, S.Vokos'², I. Y. Al-Qaradawi ${ }^{1}$, Z. Said ${ }^{3}$, T. Kerr', R. Hinrichs ${ }^{5}$ \\ ${ }^{1}$ Department of Mathematics, Statistics and Physics, Qatar University, Doha, Qatar, 2 Physics Department, Seattle Pacific \\ University, Seattle WA USA, ${ }^{3}$ College of the North Atlantic, Department of Engineering Technology, Doha Qatar, ${ }^{4}$ College of \\ Education, Qatar University, Doha Qatar, ${ }^{5}$ Physics Department, SUNY Oswego NY USA \\ For correspondence: R. Hinrichs: rahinrichs@gmail.com
}

\begin{abstract}
It has been recognized for many years that the topic of energy is an avenue that provides students with engaging opportunities to experience how science is actually done. As a topic, energy cuts across many disciplines and also provides many opportunities to develop a series of practices or skills of how science works. Inquiry is certainly more than hands-on science and is in part a state of mind - that of inquisitiveness. How do we create an educational system that exploits the natural curiosity of children? This paper will discuss the initiation of a three-year, multifaceted project in Qatar that seeks to strengthen teachers' understandings of energy, foster scientific curiosity, and enhance lab-based and class-based inquiry skills. Of importance to this study is an understanding of students' and teachers' views on the Nature of Science (NOS); a survey (VOSTS) of 1100 secondary school students and teachers in Qatar allowed us to look at both weaknesses and strengths. Part of our approach was the creation of an Energy Institute, begun in summer 2013. Opportunities and obstacles will be discussed as well as strategies that seem to have the most impact.
\end{abstract}

Keywords: energy, inquiry, curiosity, industry

\section{Introduction}

Energy is one of the major building blocks of modern society. It pervades all sectors of society. Economic development and improved standards of living are complex processes that share a common denominator: the availability of an adequate and reliable supply of energy. Political events over the last many decades have made it very clear how crucial energy is to the everyday functioning of any society. Energy is also a basic concept in all the sciences and engineering disciplines; the conservation of energy is a fundamental principle and its application helps us understand many facets of science. A system's total energy changes only by the transfer of energy into or out of that system. When discussing science education, the concept of energy is one of the core concepts, Constantinou and Papadouris (2012), Hinrichs and Kleinbach (2011). Understanding energy means understanding energy resources and their uses, as well as the environmental consequences of their use. Technologies to transfer energy from one object to another are of interest to students, and energy does serve as a bond in many areas of physics. As physics is an experimental science, there are many opportunities to have students be involved in both hands-on and minds-on activities in the area of energy.

In the eyes of many, science education has primarily emphasized science content alone without much attention to either the experiments that motivate the construction of a concept nor the skills or practices that went into the development of that idea, National Research Council (1996). Qatar has a well written set of curriculum standards that cover most topics in the field of physics. However a good deal of attention in these standards is paid to learning all there is to know about that topic; this unfortunately leaves many students with the impression that science is simply a body of isolated facts. Coverage is on breadth rather than depth. Low scores on international $4^{\text {th }}$ and $8^{\text {th }}$ grade science 
achievement tests (TIMSS - 2007 and PISA - 2009) provide evidence that basic changes are needed. In interviews with secondary school science teachers in Doha in an earlier study, we found little evidence of prolonged, sustained, coherent (age-appropriate) investigations. Most laboratory experiments had as a primary instructional goal the verification of some principle that the teachers had already lectured upon. This practice reinforced the students' perception (identified through our work and other studies (Ibrahim et al, 2009 and Khishfe and Abd-El-Khalick, 2002) on the Nature of Science) that science consists of memorizing a set of formulae and facts, which scientists primarily discovered through the sterile, uncreative act of pursuing a fixed recipe (called the scientific method).

Recent international science education reports have questioned whether our students are losing some of the abilities to think critically, and do problem solving in a broader context. Most students go onto non-science and non-engineering disciplines, but still must be able to evaluate things scientifically. A recent US National Research Council's paper (National Research Council, 2011) states that

"The overarching goal of our framework for K-12 science education is to ensure that by the end of 12th grade, all students have some appreciation of the beauty and wonder of science; possess sufficient knowledge of science and engineering to engage in public discussions on related issues; are careful consumers of scientific and technological information related to their everyday lives; are able to continue to learn about science outside school; and have the skills to enter careers of their choice, including (but not limited to) careers in science, engineering, and technology.

Currently, K-12 science education in the United States fails to achieve these outcomes, in part because it is not organized systematically across multiple years of school, emphasizes discrete facts with a focus on breadth over depth, and does not provide students with engaging opportunities to experience how science is actually done."

This same report advanced the ideas that science education should be built around 3 facets:

- Science and engineering practices

- Cross-cutting concepts

- Core ideas in the disciplinary areas

Energy is one of the cross-cutting concepts and as a topic fits into all three of these dimensions. "Practices" refer to the skills and understanding of how science (as well as engineering) works. These practices include

1. Asking questions

2. Developing and using models

3. Planning and carrying out investigations

4. Analyzing and interpreting data

5. Using mathematics and computational thinking

6. Constructing explanations

7. Engaging in arguments from evidence

8. Obtaining, evaluating, and communicating information.

One of the things we have learned from our interaction with schools in Qatar is that it is hard to talk about inquiry-based learning if the teachers have not experienced such an approach themselves. Inquiry is more than hands-on science (Yager, 2000).

There is certainly a spectrum of approaches to inquiry-based learning (Leonard and Penick, 2009). This can go from structured inquiry (students investigate a teacher-presented question through a prescribed procedure) to guided inquiry (students investigate a teacher-presented question using student-designed procedures) to open inquiry (students investigate a question that is student 
formulated). Inquiry is certainly at the heart of science. Emphasis on laboratory work can provide an environment in which students can develop good skills in being able to ask scientific questions (Sokoloff et al, 1999). However, the number of labs given in Qatari classes in any semester is small, so those opportunities need to be expanded. Part of the problem is due to unfamiliarity with equipment, lack of training in how to integrate such lab experiences into the required curriculum, and continued emphasis on exams testing breadth, not depth. On a positive note, the number of science technicians in Qatari schools has increased. Energy is a prime example of a topic that not only cuts across disciplinary lines but also lends itself to good laboratory work that can encourage inquiry.

Inquiry is in part a state of mind - that of inquisitiveness. Most young children are naturally curious. They ask why and how questions. However, if we as adults put too much emphasis on a result, an answer, and dismiss their questions as uninteresting, or even silly, students can lose this gift of curiosity. The challenge for all who want to improve education is to create an educational system that exploits the natural curiosity of children so that they maintain their motivation for learning through their school years and beyond. Do students have fewer questions after instruction than before? Are they less curious after instruction than before, and have more negative views of science and science careers after instruction? Traits like curiosity seem to be as important as intelligence in determining how well students do. For some, curiosity is one of the driving engines for innovation. There are few surveys that try to measure a child's curiosity, and correlate them with an interest in science. As expected, there is a positive correlation between curiosity and an interest in science, especially among elementary students (Harty and Beall, 1984). Curiosity is seen by some to be basically a hunger for exploration. The real challenge is to discover what blocks curiosity, and leads to a situation of fixed ideas, lack of innovation, and lack of "fun" in learning. Operationally, elementary school children are said to demonstrate curiosity when they react positively to new, strange, incongruous, or mysterious elements in their environment, exhibit a need or desire to know more about themselves and their environment, and scan their surroundings seeking new experiences (Huff, 2011).

\section{Objectives and Significance}

"Energy City" is a three-year, multifaceted project that seeks to strengthen teachers' and students' understandings of energy, foster scientific curiosity, enhance lab-based and class-based inquiry skills. It will further enhance dialogue and links between industry and education. Emphasis is on researchbased hands-on and minds-on experiences for both teachers and students that reflect authentically the nature of the scientific enterprise (Nordine et al, 2010). Twenty five physics and physical science teachers were selected from 12 Qatar independent (government) secondary (9-12 grade) and preparatory (6-8 grade) schools for this study. School lab technicians will be included (as a separate group) in the project in year two, as well as students. One of the mid-term goals is the establishment of an Institute in Energy Education for teachers, hence the proposal title "Energy City". The Institute will be institutionalized so as to continue past the end of the grant. We also aspire to increase the number of college-ready students who will pursue STEM degrees. Besides immersing the students in research and good science, teachers will be developing and disseminating instructional models that enhance student inquiry skills and scientific curiosity.

This project is a focused extension of the previously funded Qatar National Research Foundation's (QNRF) “National Priorities Research Program" entitled "Epistemology, Formative Assessment, and Energy: Understanding and strengthening students' and teachers' views of science and energy;" QSTEP (Qatar Science Teachers Energy Project) in short. Our current project seeks to build upon the knowledge and skills of teachers of physics (grades 6-12) at independent schools by leveraging Qatar's energy themes. We are examining the impact of strategies upon the understanding of the subject matter as well as engaging teachers and students in lab investigations. As we have learned over the last several years, frequent interaction and purposeful mentoring of teachers is crucial to 
their growth. So classroom visitation is as important an ingredient of this effort as content and pedagogical workshops.

With respect to significance, the timing of this project is very appropriate. Presently Qatar's Supreme Education Council (SEC) is conducting a review of its science curriculum standards. Appropriately, the U.S. National Academy of Sciences has released a report (National Research Council, 2011) that proposes a framework for K-12 Science Education that weighs in heavily on depth (as opposed to breadth) in core ideas (big pictures) and the integration of such knowledge and abilities with practices needed to engage successfully in scientific inquiry and engineering design. We feel that this project helps to advance but also explore such an approach with today's Qatari teachers. This project also serves the "Qatar National Vision 2030" plan by leveraging Qatar's foundational energy themes and adding to the research base on how students learn science and how instructional interventions foster scientific curiosity in a knowledge-based society.

\section{Preliminary Data or Studies}

As we venture into a more detailed description of this project, it is important to mention several issues regarding the context into which this research proposal was introduced. In the fall of 2006, a series of workshops for high school physics teachers was begun by two of this paper's authors. These were some of the first such workshops held in Qatar that were content driven, although technology and pedagogy were also dealt with. At each workshop there were about 50 high school physics teachers in attendance, mainly from public schools. Visitations to local high schools, which are singlegender, in preparation for these workshops allowed us to talk to the teachers and see their facilities. Many un-opened boxes of nice lab equipment and a desire of the teachers to go beyond their present teaching methods stood out. The outcome of these workshops was a group of better prepared physics teachers in content, pedagogy and technology. Active learning and inquiry based teaching was always on display, with material coming from physics education research. This project, QSTEP, sought to study Middle Eastern students' and teachers' views on the Nature of Science (NOS) as well as implement a formative assessment (FA) instructional cycle with these teachers.

The Nature of Science refers to the epistemology (what knowledge is and how it is acquired) of science, science as a way of knowing, and the values and beliefs inherent to scientific knowledge and its development. An understanding of NOS is advocated as a central component of scientific literacy, and is emphasized in national reform documents worldwide, including Qatar Curriculum Standards. There is very little research on student views of the NOS in the Middle East, and more specifically, in Qatar. To meet this need, three internationally accepted surveys that deal with views on the nature of science (Lederman et al, 2002, and Aikenhead and Ryan, 1992) were given to over 1000 students and teachers in Doha Independent schools - both preparatory and secondary schools. From the analysis of this data (under the direction of Dr. Fouad Abd-El-Khalick of the University of Illinois, UrbanaChampaign), we found that the Qatari students and their teachers were quite similar to those tested in other Middle Eastern countries, or for that matter, similar to worldwide results (see Table 1). Not much is formally taught about the nature of science, so most of the views were naïve, as opposed to having some merit or being informed views. Strengths for the Qatari students were observed in the empirical aspect of NOS. They indicated that science is testable, experimental, and based on observations. They also recognized that science is reliable and durable, but never absolute or certain. Facts, theories, laws are subject to change. But the students (and their teachers) also held beliefs that a scientist's personal beliefs do not affect the scientific knowledge they produce. An informed view holds that science is affected by various cultural elements and spheres, including social fabric, worldview, religion and political and economic factors. Another interesting view (but expected) was that both students and teachers believed in the myth of the "Scientific Method". This belief holds that there is a recipe procedure for doing science. Such a belief can hamper the attributes of creativity and 
curiosity in the lives of scientists. One of our conclusions is that explicit attention to the NOS should be introduced to upper primary grade students (and their teachers). Perceptions about the NOS among older students are difficult to change.

Another part of this study is the establishment of an ongoing Energy Institute. We recognize that the creation of an Energy Institute needs to be integrated into and subject to present Qatar curriculum standards and cultural norms. Consequently we drew upon the experiences of the project teachers. Experience from the QSTEP project was very important here. We know that more direct contact with these teachers is important - they have many responsibilities and loads to carry. Consequently, we hired a local full-time research associate. Also, we employ (on a part-time basis) two consultants who are now administrators within the SEC, but former high school physics teachers from local boys and girls schools, and who have been involved with QSTEP. We also decided to hold the Energy Institute outside of Qatar - to not only make the commitment of two weeks of summer time more attractive for the teachers but also to give them the opportunity to be more focused upon the project, outside of family obligations. The first Energy Institute was held in Istanbul in August 2013; about 25 teachers attended. The next one will be held in Cyprus in August 2014.

The objectives of the ongoing or institutionalized Energy Institute are to:

- Understand basic principles of energy conversion and power production

- Describe and compare present and future commercial energy sources in Qatar and the world

- Identify renewable energy sources

- Evaluate environmental effects of energy production and use

- Gain experience in laboratory work through energy-related experiments and activities that encourage deductive reasoning, science applications, problem solving skills

- Develop and share energy curricula and materials

- Participate in field trips to energy facilities in Qatar

- Modify curricula so it fits in more effectively with new Qatar Curriculum Standards

- Understand inquiry-based teaching

- Provide links between school teachers and industry in Qatar for future dialogue through the creation of a Governing Board

Table 2 shows the daily schedule for the 2013 Energy Institute in Istanbul.

\section{Status of Project and Future Directions}

Let us summarize the status of this project and its current and future directions.

- Four multi-day workshops (evenings and/or Saturdays) have been held for 28 science teachers from Doha schools in the last 18 months. These workshops have covered energy transformations and "Energy Theatre" (Scherr et al, 2013), the first law of thermodynamics, overview of energy resources for Qatar and world, Energy as a framework for interpreting system changes, the aluminum industry in Qatar.

- Planning is underway for a 10-day Energy Institute to be held in Cyprus in August 2014.

- Project teachers are modifying and developing activities/lesson plans for energy topics under the guidance of research staff. These are placed in a computer cloud folder, which is accessible remotely by all participants

- Observations of teaching are now being conducted by two education associates, using a rubric developed for a previous study of teaching in Qatar. These include assessments of learning objectives, understanding, sense-making, classroom culture, as well as views on traits of curiosity.

- Establishing contacts with energy-related industries in Qatar continues. Meetings have been held with 6 companies so far. Their interest in the project has been very strong. 
A number of challenges and obstacles mark this project, as might be expected (and planned for). These include

- Rapidly changing curriculum standards and instructional expectations

- A propensity not to use a textbook

- Different cultural and societal backgrounds between teachers and students

- Significant lack of motivation among the students - especially in high school

- Workshops that teachers were mandated to attend that overlapped with our project sessions, and a large number of government-mandated professional development requirements

Some of these challenges are being met by including project teachers in planning for the second Energy Institute. Ever since the beginning of this project, the - its principal investigators have tried to encourage team efforts - our teachers are part of a research team. We have also placed more emphasis on classroom team building and science project endeavors. This is hard due to pressures on teachers with respect to obtaining scores on nation-wide exams. We emphasize that active learning and inquiry based approaches do bring out the best in students from all backgrounds and enhance an appetite and a curiosity for science. As we heard from some students, "We are not science students, we are student scientists." 
Table 1.

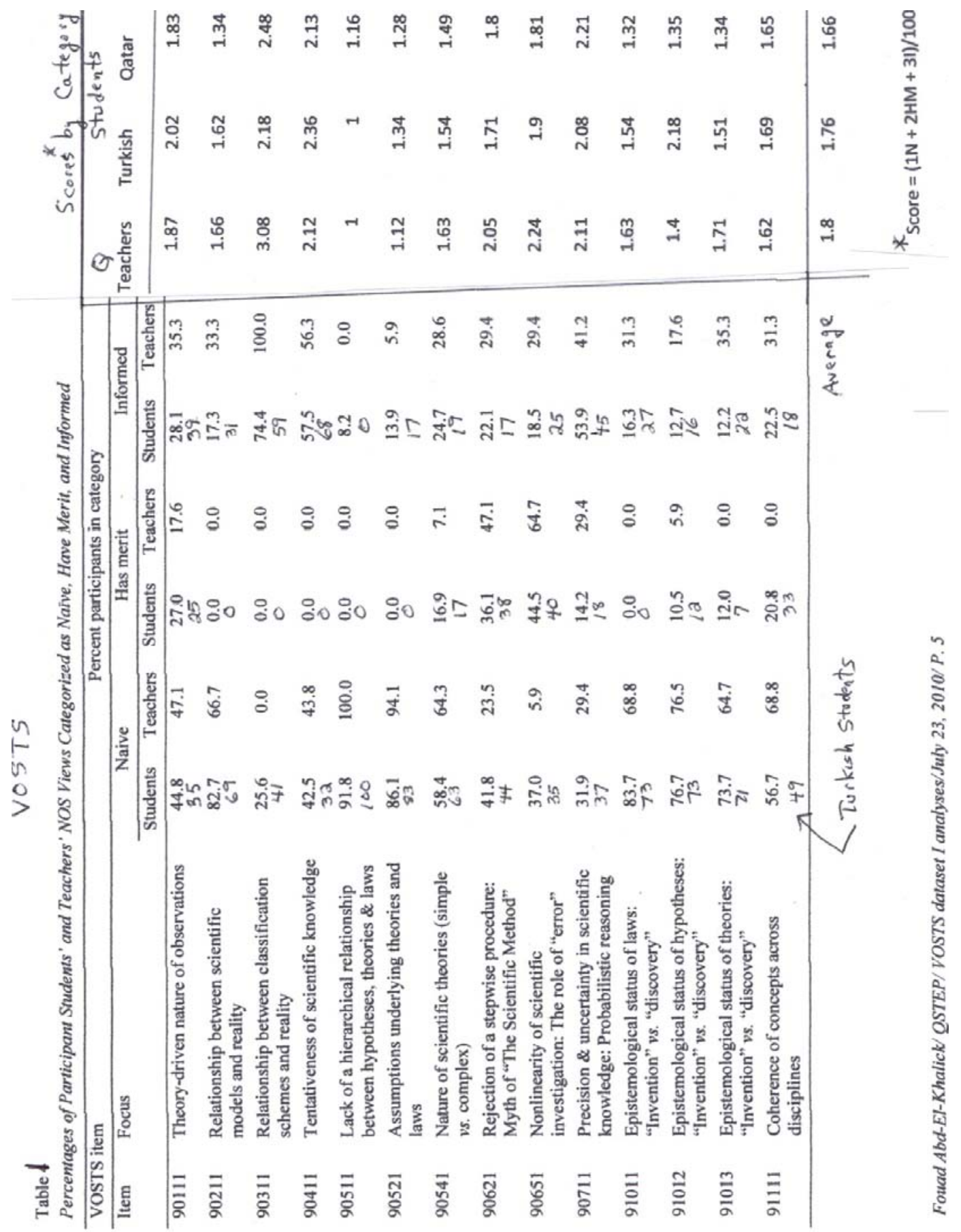


Table 2.

INSTITUTE IN ENERGY EDUCATION

Istanbul Sehir University

2013 Daily Schedule

\begin{tabular}{|c|c|c|}
\hline Sunday & $\mathrm{AM}$ & Energy Survey \\
\hline \multirow[t]{7}{*}{$8 / 25$} & & Introductions - Staff \& Participants, Objectives, Requirements \\
\hline & & Background on energy uses and trends - World, Qatar, Turkey, Palestine \\
\hline & & Name tags - Energy sources Activity \\
\hline & PM & Energy mechanics $S V$ \\
\hline & & Mechanics $L a b$ - - with sensors $R H S V$ \\
\hline & & World energy resources $R H$ \\
\hline & & Curiosity - How do we increase this in our students? \\
\hline Monday & $\mathrm{AM}$ & Laws of energy and Heat transfer $S V$ \\
\hline \multirow[t]{5}{*}{$8 / 26$} & & Presentation by representative of Vernier (Istanbul) \\
\hline & & Power Activity \\
\hline & PM & "What if?" - Energy futures Activity \\
\hline & & Vernier Equipment Presentation \\
\hline & & Oil and Gas industry overview ZS \\
\hline Tuesday & $\mathrm{AM}$ & Petrochemistry Intro, Refinery processes $\mathrm{ZS}$ \\
\hline \multirow[t]{2}{*}{$8 / 27$} & PM & Petrochemistry Activities * ZS \\
\hline & & Solar Energy Overview $\quad \boldsymbol{R H}$ \\
\hline Wednesday & $\mathrm{AM}$ & Environmental Pollution $\mathrm{ZS}$ \\
\hline \multirow[t]{2}{*}{$8 / 28$} & & Solar space \& water heating systems $\boldsymbol{R H}$ \\
\hline & PM & Energy demos Construction (House, Cooker) \\
\hline Thursday & $\mathrm{AM}$ & Electricity Generation \& Transmission $S V$ \\
\hline \multirow[t]{3}{*}{$8 / 29$} & & Biomass technologies, Recycling ZS \\
\hline & PM & Batteries \& bulbs $\mathbf{L} a \boldsymbol{b} \quad S V$ \\
\hline & & Activities construction time \\
\hline$\underline{\text { Sunday }}$ & $\mathrm{AM}$ & PV principles $\mathbf{M Z}$ \\
\hline \multirow[t]{4}{*}{$9 / 1$} & & PV Lab $\quad M Z$ \\
\hline & PM & Effective Energy teaching strategies $S V$ \\
\hline & & Insolometer Construction \\
\hline & & Activities construction time \\
\hline \multirow{5}{*}{$\frac{\text { Monday }}{9 / 2}$} & $\mathrm{AM}$ & Nuclear physics - fundamentals IQ \\
\hline & & Fission reactors $I Q$ \\
\hline & PM & Low \& high level rad wastes $I Q$ \\
\hline & & Wind energy $\boldsymbol{R H}$ \\
\hline & & Wind energy $\mathbf{L} a \boldsymbol{b}$ \\
\hline \multirow{3}{*}{$\frac{\text { Tuesday }}{9 / 3}$} & $\mathrm{AM}$ & Environmental aspects of energy use $I Q, M Z$ \\
\hline & & Solar Cooking Activity \\
\hline & PM & Solar/Wind powered vehicle competition Activity \\
\hline Wednesday & $\mathrm{AM}$ & Activity/energy demos presentations by class \\
\hline \multirow[t]{2}{*}{$9 / 4$} & PM & Energy survey, evaluation \\
\hline & & Energetic awards \\
\hline
\end{tabular}

Guiding Principles:

- Strengthen understanding of energy and its uses

- Enhance lab-based inquiry skills - develop and adapt and distribute 
- Foster more curiosity

- Explore research opportunities for students in energy

- Examine new standards and seek emphasis on practices

- Introduce more sensor-based technology

- Develop competitive energy-centered activities

- Increase time needed for curriculum work

- Develop program for technicians

\section{Acknowledgements}

This report was made possible by a National Priorities Research Program award [NPRP 5-715-1-12.] from the Qatar National Research Fund (a member of The Qatar Foundation). The statements made herein are solely the responsibility of the authors.

\section{References}

Aikenhead, G. \& A. Ryan (1992). The development of a new instrument: "Views on Science-Technology-Society" (VOSTS), Science Education 76: 477-491.

Constantinou, C. \& N. Papadouris (2012). Teaching and learning about energy in middle school: an argument for an epistemic approach.. JRST 48: 161-186

Harty, H. \& S. Beall (1984). Toward the development of a children's science curiosity measure. JRST 21:425-436.

Hinrichs, R. \& M. Kleinbach (2011). Energy: Its Use and the Environment, 5e, Boston, Cengage

Huff, T. (2011). Intellectual Curiosity and the Scientific Revolution. Cambridge Univ. Press

Ibrahim, B., A. Buffler, F. Lubben (2009). Profiles of freshman physics students' views on the nature of science. JRST 46: 248-264.

Khishfe, R. \& Abd-El-Khalick (2002). Influence of explicit and reflective vs. implicit inquiry-oriented instruction of sixth graders' views of nature of science. JRST 39:551-578.

Lederman, N., F. Abd-El-Khalick, R. Bell \& R. Schwartz (2002). Views of Nature of science questionnaire: Towards valid meaningful assessment of learner's conceptions of nature of science (VNOS), JRST 39: 497-521.

Leonard, W. \& J. Penick (2009). Is the inquiry real? The Science Teacher 76: 40-47.

National Research Council (1996). National science education standards, Washington DC, National Academy Press.

National Research Council (2011). A Framework for K-12 science education: Practices, Concepts, and Core Ideas, Washington DC, National Academy Press

Nordine, J., J. Krajcik, \& D. Fortun (2010). Transforming energy instruction in Middle school to support integrated understanding and future learning. Science Education. www.wileyonlinelibrary.com

Scherr, R., H. Close, E. Close, V. Flood, S. McKagan, A. Robertson, L. Seeley, M. Wittman, and S. Vokos. (2013). Negotiating energy dynamics through embodied action in a materially structured environment. Physics Education Research 9 (2).

Sokoloff, D., R. Thornton, \& P. Laws (1999). Real Time Physics: Active learning laboratories. NY, Wiley.

Yager, R. (2000). The Centrality of inquiry for teaching and learning science in Inquiry: the key to exemplary science, Washington DC, NSTA Press. 